\title{
The chelate formation of thorium with 1, 2-naphthoquinone, 1- oxime
}

\author{
G. S. Jagtap, N. S. Suryawanshi, K. D. Jadhav and R. G. Sarawadekar* \\ Bharati Vidyapeeth Deemed University, Pune (India) \\ Yashwantrao Mohite College, Pune 411038
}

\begin{abstract}
Thorium chelate of 1,2-naphthoquinone, 1-oxime was synthesized. The vibrational wave numbers of thorium with 1,2-naphthoquinone, 1-oxime have been calculated using Gaussian 09 software code, employing RHF / SDD basis set and IR data is compared with experimental values. The predicted infrared intensities and Raman activities are reported. The calculated frequencies are in good agreement with the experimental values. The calculated geometrical parameters are also given. The study is extended to calculate the HOMO-LUMO energy gap, Ionization potential (I), Electron affinity ( A ), Global hardness ( $\eta$ ), chemical potential $(\mu)$ and global electrophilicity $(\omega)$. The calculated HOMO-LUMO energies show the charge transfer occurs in the molecule. Optimized geometrical parameters of the title compound are in agreement with similar reported structures.
\end{abstract}

Keywords: 1-2 naphthoquinone, 1-oxime, IR, HF, Energy gap, Thorium monoximate

\section{Introduction}

It was shown that 2-nitroso 1- naphthol ( 1 -oxime) $\left(\mathrm{pK}_{\mathrm{a}}=7.24\right)$ is a stronger acid than 1-nitroso 2naphthol ( 2-oxime) $\left(\mathrm{pK}_{\mathrm{a}}=7.63\right)(1)$. The chemistry of coordination compounds has shown a rapid development in diverse displines as a result of the possible use of these new compounds in biological applications. Oximes have often been used as chelating ligands in the field of coordination chemistry and their metal complexes have been of great interest for many years. Oxime metal chelates are biologically active (2). Quinones and naphthoquinones are widely distributed in nature and play a vital role in certain cellular functions. Owing to the large variety of coordination geometries, coordination numbers, and modes of interactions with their ligands, metal complexes or mostly chelates give access to a different field of pathways in cancer treatment than do organic compounds. The discovery of the anticancer properties of cisplatin was a breakthrough event as far as interest in metal complexes was concerned (3). The structure of 1-2 naphthoquinone 1-oxime is examined by use of the HF (6 -31 G*level), density functional theory DFT (6 -31 G* level) \& hybrid functional B3LYP. Using the optimized structure of the titled compound IR, NMR, and ultraviolet data is calculated and compared with experimental data. It shows good relation between theoretically calculated IR wave numbers \& observed values for Mid - Far IR data (4). The polarographic behavior of the 1, 2-naphthoquinone has been investigated in the $\mathrm{pH}$ range 3 to 14. All of the compounds produce well defined polarographic reduction waves which can be used for analytical purposes. Polarographic evidence indicates that the monoximes and the dioximes exhibit tautomerism (5). Ab initio, Hartree- Fock and Density Functional Theoretical study of vibrational spectra of zirconium chelate of 1, 2- naphthoquinone-1, oxime have been reported by G. S. Jagtap et.al. (6).

This paper describes synthesis and vibrational spectra of thorium chelate of 1, 2-naphthoquinone 2-oxime calculated by HF basis set, the data is compared with experimental values. Geometrical parameters, Mulliken atomic charges and HOMO - LUMO energy gap of the chelate is reported.

\section{Materials and Methods}

The ligand 1, 2-naphthoquinone 1-xime or 1-nitroso 2- naphthol is used as it is supplied by (Fluka, chemicals). A stock solution of thorium nitrate $\left[\mathrm{Th}(\mathrm{NO} 3)_{4}\right]$ is prepared by using AR grade chemicals. Deionised water is used during synthesis.

\subsection{Synthesis of metal chelate}

The chelate was prepared by mixing metal salt solution and ligand in 1: 1 proportion. The mixture was constantly stirred for one hour on magnetic stirrer. The $\mathrm{pH}$ of the mixture was maintained, in between 5.0 6.0 by adding ammonia solution to it. Warm the mixture on water bath for about 15 minutes. On cooling it was filtered and found to be coloured. 
The chelate formation of thorium with 1, 2-naphthoquinone, 1-oxime

\subsection{Instrumental Analysis}

Elemental analysis was carried out with a Perkin Elmer 2400 series for C, H, and O \& N. The IR spectra was recorded on a Thermo Fischer FTIR spectrophotometer iS5 model in a $\mathrm{KBr}$ matrix and in the range of $4000-400 \mathrm{~cm}^{-1}$ as well as in the range of $1000-300 \mathrm{~cm}^{-1}$.

\subsubsection{Computational details}

The entire calculations conducted in the present work were performed at Hartree - Fock (HF/ SDD) basis set in the Gaussian 09 software code. The geometries were first determined at the Hartree - Fock level of employing SDD basis set $(7,8)$.

The wave number value computed theoretically contains known systematic error due to the negligence of electron correlation. We have used the scaling factor value of 0.9393 for HF /SDD basic set. The absence of imaginary wave number on the calculated Vibrating Spectrum confirms that the structure corresponds to minimum energy. HOMO-LUMO energy gap and other related molecular parameters are calculated.

\section{Results and Discussion}

The infra red absorption frequencies of $\mathrm{Th}(\mathrm{NQO})_{2}$ are analysed on the basic of the characteristics vibration of hydroxyl, Carbonyl, $\mathrm{C}=\mathrm{N}, \mathrm{N}-\mathrm{O}$ and Th- $\mathrm{N}$ modes. The computed vibrational wave numbers of IR with intensity are used for identifying modes unambiguously. The harmonics vibrational frequencies calculated for Th (NQO) $)_{2}$ at HF using the SDD basis set have been presented in Table -1. It can be noted that calculated results are harmonics frequencies while the observed contains unharmonic contribution also. The value of the wave number is lower than the former due to anharmonicity. Comparison between the calculated and the observed vibration spectra help us to understand the observed spectral frequency.

Table 1: Infra red Wave numbers of Thorium1-oximate

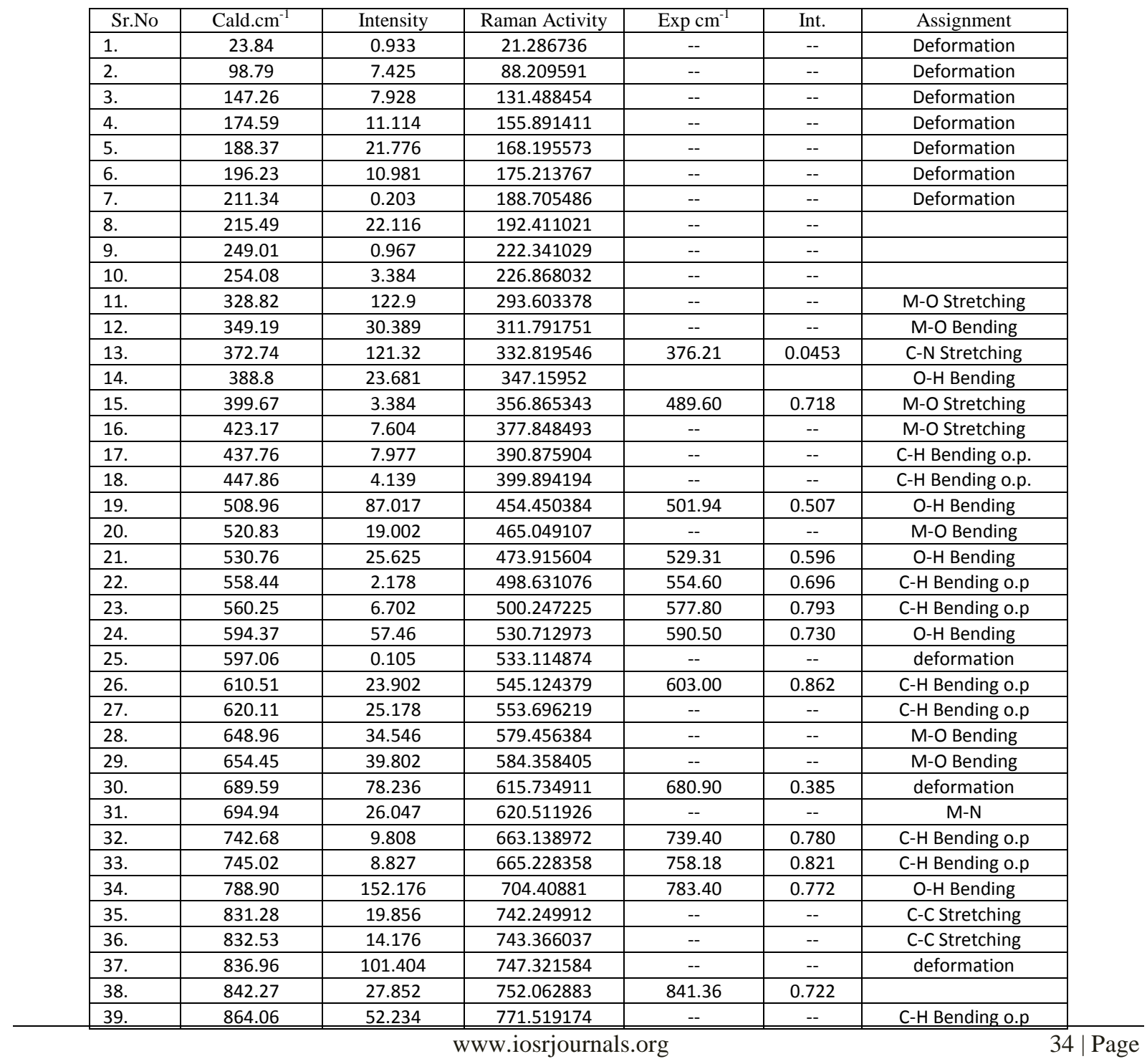


The chelate formation of thorium with 1, 2-naphthoquinone, 1-oxime

\begin{tabular}{|c|c|c|c|c|c|c|}
\hline 40. & 864.60 & 26.269 & 772.00134 & -- & -- & C-H Bending o.p \\
\hline 41. & 887.34 & 19.067 & 792.305886 & 888.20 & 0.722 & $\mathrm{C}-\mathrm{H}$ Bending o.p \\
\hline 42. & 888.99 & 3.801 & 793.779171 & -- & -- & $\mathrm{C}-\mathrm{H}$ Bending o.p \\
\hline 43. & 938.97 & 87.821 & 838.406313 & 930.60 & 0.169 & $\mathrm{C}-\mathrm{H}$ Bending o.p \\
\hline 44. & 940.61 & 134.87 & 839.870669 & & & $\mathrm{C}-\mathrm{H}$ Bending o.p \\
\hline 45. & 989.33 & 10.91 & 883.372757 & -- & -- & \\
\hline 46. & 989.56 & 5.025 & 883.578124 & -- & -- & \\
\hline 47. & 1007.42 & 10.118 & 899.525318 & -- & -- & C-H Bending o.p \\
\hline 48. & 1018.38 & 1.4897 & 909.311502 & -- & -- & $\mathrm{C}-\mathrm{H}$ Bending o.p \\
\hline 49. & 1106.25 & 0.494 & 987.770625 & 1086.27 & 0.652 & $\mathrm{C}-\mathrm{H}$ Bending o.p \\
\hline 50. & 1108.75 & 0.951 & 990.002875 & 1101.00 & 0.668 & $\mathrm{C}-\mathrm{H}$ Bending o.p \\
\hline 51. & 1121.19 & 56.567 & 1001.110551 & -- & -- & C-C stretching \\
\hline 52. & 1126.75 & 34.831 & 1006.075075 & -- & & C-C stretching \\
\hline 53. & 1135.00 & 3.03 & 1013.4415 & -- & -- & $\mathrm{C}-\mathrm{H}$ Bending o.p \\
\hline 54. & 1140.01 & 2.664 & 1017.914929 & 1137.56 & 0.641 & C-H Bending o.p \\
\hline 55. & 1155.38 & 1.579 & 1031.638802 & 1153.97 & 0.892 & C-H Bending o.p \\
\hline 56. & 1178.41 & 28.939 & 1052.202289 & 1173.73 & 0.746 & $\mathrm{~N}-\mathrm{O}$ stretching \\
\hline 57. & 1183.92 & 22.953 & 1057.122168 & -- & -- & $\mathrm{N}-\mathrm{O}$ stretching \\
\hline 58. & 1203.34 & 6.03 & 1074.462286 & 1216.08 & 1.117 & C-H Bending \\
\hline 59. & 1234.76 & 36.16 & 1102.517204 & 1235.80 & 0.623 & $\mathrm{C}-\mathrm{H}$ Bending i.p \\
\hline 60. & 1234.97 & 21.513 & 1102.704713 & -- & -- & $\mathrm{C}-\mathrm{H}$ Bending i.p \\
\hline 61. & 1272.69 & 295.78 & 1136.384901 & 1260.83 & 0.595 & C-C stretching \\
\hline 62. & 1276.43 & 17.158 & 1139.724347 & -- & -- & $\mathrm{C}-\mathrm{H}$ Bending i.p \\
\hline 63. & 1293.40 & 8.155 & 1154.87686 & 1293.80 & 0.468 & $\mathrm{C}-\mathrm{H}$ Bending i.p \\
\hline 64. & 1301.11 & 44.614 & 1161.761119 & -- & -- & $\mathrm{C}-\mathrm{H}$ Bending i.p \\
\hline 65. & 1315.08 & 3.136 & 1174.234932 & 1310.05 & 0.854 & $\mathrm{~N}-\mathrm{O}$ Stretching \\
\hline 66. & 1319.46 & 7.436 & 1178.145834 & -- & -- & C-C stretching \\
\hline 67. & 1352.35 & 27.845 & 1207.513315 & 1344.56 & 0.966 & $\mathrm{C}-\mathrm{H}$ Bending i.p \\
\hline 68. & 1361.95 & 5.062 & 1216.085155 & -- & -- & $\mathrm{C}-\mathrm{H}$ Bending i.p \\
\hline 69. & 1399.10 & 57.883 & 1249.25639 & 1384.34 & 1.279 & $\mathrm{C}-\mathrm{H}$ Bending i.p \\
\hline 70. & 1400.93 & 36.446 & 1250.890397 & 1404.22 & 1.073 & $\mathrm{C}-\mathrm{H}$ Bending i.p \\
\hline 71. & 1461.15 & 0.782 & 1304.660835 & -- & -- & C-C stretching \\
\hline 72. & 1463.29 & 3.442 & 1306.571641 & 1454.65 & 0.592 & $\mathrm{C}-\mathrm{H}$ Bending i.p \\
\hline 73. & 1490.81 & 19.061 & 1331.144249 & 1477.82 & 0.694 & O-H Bending \\
\hline 74. & 1498.75 & 19.426 & 1338.233875 & -- & -- & C-C stretching \\
\hline 75. & 1520.52 & 7.031 & 1357.672308 & 1524.57 & 0.911 & $\mathrm{O}-\mathrm{H}$ Bending \\
\hline 76. & 1562.67 & 83.886 & 1395.308043 & 1557.50 & 1.292 & C-O Stretching \\
\hline 77. & 1568.74 & 133.628 & 1400.727946 & -- & -- & C-O Stretching \\
\hline 78. & 1584.10 & 84.426 & 1414.44289 & 1580.40 & 0.329 & $\mathrm{O}-\mathrm{H}$ Bending \\
\hline 79. & 1621.60 & 110.588 & 1447.92664 & 1609.65 & 1.073 & $\mathrm{C}-\mathrm{H}$ Bending i.p \\
\hline 80. & 1624.00 & 24.559 & 1450.0696 & -- & -- & C-C stretching \\
\hline 81. & 1654.30 & 44.195 & 1477.12447 & 1647.70 & 0.545 & C-C stretching \\
\hline 82. & 1654.96 & 3.726 & 1477.713784 & -- & -- & C-C stretching \\
\hline 83. & 1707.27 & 28.746 & 1524.421383 & -- & -- & $\mathrm{C}-\mathrm{N}$ stretching \\
\hline 84. & 1722.45 & 4.71 & 1537.975605 & -- & -- & C-O stretching \\
\hline 85. & 1747.15 & 201.235 & 1560.030235 & 1746.10 & 0.884 & C-C stretching \\
\hline 86. & 1750.47 & 104.291 & 1562.994663 & -- & -- & C-C stretching \\
\hline 87. & 1803.65 & 70.667 & 1610.479085 & -- & -- & C-C stretching \\
\hline 88. & 1807.98 & 71.047 & 1614.345342 & -- & -- & $\mathrm{C}-\mathrm{O}$ stretching \\
\hline 89. & 1826.90 & 356.751 & 1631.23901 & -- & -- & C-N stretching \\
\hline 90. & 1837.13 & 89.831 & 1640.373377 & -- & -- & C-N stretching \\
\hline 91. & 1885.21 & 0.984 & 1683.304009 & -- & -- & C-C stretching \\
\hline 92. & 1886.08 & 0.824 & 1684.080832 & -- & -- & C-C stretching \\
\hline 93. & 1920.72 & 33.52 & 1715.010888 & -- & -- & C-C stretching \\
\hline 94. & 1923.07 & 89.096 & 1717.109203 & 1944.30 & 0.837 & C-C stretching \\
\hline 95. & 3391.55 & 9.168 & 3028.314995 & 3247.80 & 0.240 & $\mathrm{C}-\mathrm{H}$ stretching \\
\hline 96. & 3394.27 & 5.116 & 3030.743683 & -- & -- & $\mathrm{C}-\mathrm{H}$ stretching \\
\hline 97. & 3400.34 & 3.233 & 3036.163586 & -- & -- & C-H stretching \\
\hline 98. & 3402.25 & 3.736 & 3037.869025 & -- & -- & C-H stretching \\
\hline 99. & 3407.15 & 42.564 & 3042.244235 & -- & -- & C-H stretching \\
\hline 100. & 3410.00 & 31.001 & 3044.789 & -- & -- & C-H stretching \\
\hline 101. & 3425.22 & 34.35 & 3058.378938 & -- & -- & C-H stretching \\
\hline 102. & 3427.13 & 40.34 & 3060.084377 & -- & -- & $\mathrm{C}-\mathrm{H}$ stretching \\
\hline 103. & 3428.04 & 32.9 & 3060.896916 & -- & -- & $\mathrm{C}-\mathrm{H}$ stretching \\
\hline 104. & 3430.02 & 51.187 & 3062.664858 & -- & -- & $\mathrm{C}-\mathrm{H}$ stretching \\
\hline 105. & 3436.92 & 105.19 & 3068.825868 & -- & -- & $\mathrm{C}-\mathrm{H}$ stretching \\
\hline 106. & 3484.14 & 40.911 & 3110.988606 & -- & -- & $\mathrm{C}-\mathrm{H}$ stretching \\
\hline
\end{tabular}


The chelate formation of thorium with 1, 2-naphthoquinone, 1-oxime

\begin{tabular}{|l|c|c|c|c|c|c|}
\hline 107. & 3902.01 & 46.244 & 3484.104729 & 3904.00 & 0.553 & O-H stretching \\
\hline 108. & 3914.88 & 188.044 & 3495.596352 & 3912.70 & 0.599 & O-H stretching \\
\hline
\end{tabular}

O-H vibrations

The hydroxyl $\mathrm{OH}$ group provides four normal vibrations, $v \mathrm{OH}, \delta \mathrm{OH}$ and $\gamma \mathrm{OH}$, of which not only the stretching vibration but also the out-of-plane deformation is good group vibrations

(9). HF level calculations give the $\mathrm{vOH}$ mode at 3902.01 and $3914.88 \mathrm{~cm}^{-1}$ and we observed these values at 3904.00 and $3912.70 \mathrm{~cm}^{-1}$. The moderate to strong absorption at $1350 \pm 40 \mathrm{~cm}^{-1}$ in the spectrum of phenol is assigned to $\delta \mathrm{OH}$ mode (10). In the FTIR spectrum of title compound, the vibration at 1344.56 is observed for $\delta \mathrm{OH}$ mode. This band is predicted by $\mathrm{HF}$ at $1400.93 . \mathrm{cm}^{-1}$. The $\gamma \mathrm{OH}$ mode is observed in the FTIR spectrum at $376.21 \mathrm{~cm}^{-1}$. The vibrations for $\gamma \mathrm{OH}$ are predicted by $\mathrm{HF}$ at $388.80 \mathrm{~cm}^{-1}$.

\section{C-H vibration}

The Naphthalene structure shows the presence of structural vibration in the region 3250-2950 $\mathrm{cm}^{-1}$ which is characteristics for the zero identification of C-H stretching vibration. The region $3250-3100 \mathrm{~cm}^{-1}$ is for symmetric stretching. and $3100-2950 \mathrm{~cm}^{-1}$ for are asymmetric stretching modes of vibration.(11). For most cases, the naphtholic $\mathrm{C}-\mathrm{H}$ vibration absorption bands are usually weak and it is too weak for detection. In the present work, for the Th(NQO $)_{2}$ the FTIR band is observed at $3247.8 \mathrm{~cm}^{-1}$ have been assigned to C-H stretching vibration. The HF level predicted absorptions at 3391.55, 3394.27, 3400.34, 3402.25, 3407.15, 3410.00, $3425.22,3427.13,3428.04,3430.02,3436.92$ and $3484.14, \mathrm{~cm}^{-1}$.

The title compound has both $\mathrm{C}-\mathrm{H}$ out of plane and in plane bending vibration. The out of plane bending mode of C-H vibration of $\mathrm{Th}(\mathrm{NQO})_{2}$ is predicted at $437-648,742-1155 \mathrm{~cm}^{-1}$ and in experimental values found at $554-603,739-1153 \mathrm{~cm}^{-1}$. These frequencies are well in agreement with the experimental and predicted data. HF level and SDD basis shows this region which gives number of vibration and are comparable with experimental results as shown in Fig 1. In plane bending vibration, the regions is predicted at $1234-1463 \mathrm{~cm}^{-1}$ which is comparable with the experimental recorded data at $1272-1454 \mathrm{~cm}^{-1}$.

\section{$\mathbf{C}=\mathbf{N}$ Vibrations.}

The stretching frequency of $\mathrm{C}=\mathrm{N}$ bond is observed at 1700.2 and $1693.8 \mathrm{~cm}^{-1}$, in the FTIR spectra of $\mathrm{Th}(\mathrm{NQO})_{2}$ while these are predicted by HF/ SDD at 1923.07 and $1707.27 \mathrm{~cm}^{-1}$. The bending frequency of $\mathrm{C}=\mathrm{N}$ is found in the FTIR spectrum at $797.2 \mathrm{~cm}^{-1} 1$ while $\mathrm{HF} / \mathrm{SDD}$ predicted at 831.28 and $372.74 \mathrm{~cm}^{-1} 1$. The $\mathrm{V}(\mathrm{C}=\mathrm{N})$ in chelates shows lower frequency owing to elongation of these bonds on co-ordination.

\section{N-O Bending Vibration.}

The observation of $\gamma(\mathrm{N}-\mathrm{O})$ wave number is not observed in the FTIR spectrum. HF/SDD level predicted IR frequencies at $196.23,188.37$ and $98.79 \mathrm{~cm}^{-1}$. The absorption of this $\gamma(\mathrm{N}-\mathrm{O})$ at higher wave number indicates that this bond is significantly shorter in the chelates. The higher wave length of the $\mathrm{N}-\mathrm{O}$ indicates that nitroso atoms of the oxime group coordinate to the centre $(12,13)$.

\section{N-O Stretching Vibration}

The observation of (N-O) stretching vibration is found at $1192.2 \mathrm{~cm}^{-1}$ while HF/SDD level predicted IR frequencies at 1178.41 and $1183.92 \mathrm{~cm}^{-1}$.

\section{Th-N Stretching.}

The frequencies of Th-N stretching are not observed in the FTIR spectrum but the predicted IR values are at $196.23 \mathrm{~cm}^{-1}$ by HF level.

Th-N bending vibration

The IR absorption frequencies of Th- $\mathrm{N}$ bending is predicted at $174.89 \mathrm{~cm}^{-1}$ with $\mathrm{HF}$ level. 


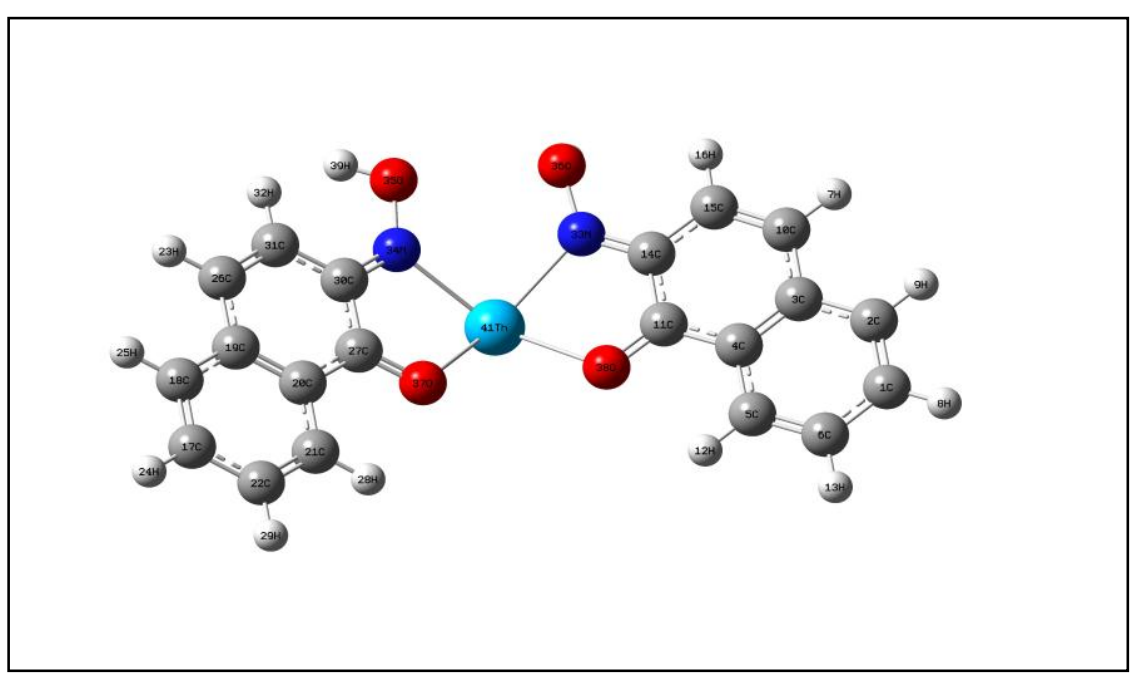

Molecular geometry.

Fig.1 Molecular structure of thorium 1-oximate

The optimized structure parameters of Th (NQO) $)_{2}$ calculated by ab initio, HF/SDD basis set are listed in Table 2 in accordance with the atom numbering scheme given in Fig -1. The values of bond length in $\mathrm{A}^{0}$, bond angles and dihedral angles in degree are given in Table 2.

Table No:-2 Bond Length and Bong Angle and Dihedral Angle of Th1-oximate

\begin{tabular}{|c|c|c|c|c|c|}
\hline Bond & $\begin{array}{c}\text { Bond } \\
\text { Length A }\end{array}$ & Bong Angle & $(0)$ & Dihedral Angle & $\mathrm{A}^{0}$ \\
\hline H41-O39 & 0.96 & H41-O39-N34 & 109.472 & H41-O39-N34-C27 & 90.207 \\
\hline H40-O38 & 0.96 & H40-O38-N35 & 109.471 & H40-O38-N35-C11 & 149.792 \\
\hline O39-N34 & 1.36 & O39-N34-C27 & 123.707 & O39-N34-C27-C20 & -8.688 \\
\hline O38-N35 & 1.36 & O38-N35-C11 & 123.707 & O38-N35-C11-C4 & 8.688 \\
\hline O37-C14 & 1.287 & O37-C14-C11 & 120.490 & O37-C14-C11-C4 & -178.644 \\
\hline O36-C30 & 1.287 & O36-C30-C27 & 120.490 & O36-C30-C27-C3 & 178.644 \\
\hline N35-C11 & 1.305 & N35-C11-C4 & 121.392 & N35-C11-C4-C3 & -179.938 \\
\hline N34-C27 & 1.305 & N34-C27-C20 & 121.392 & N34-C27-C20-C19 & 179.937 \\
\hline Th33-N34 & 2.297 & O39-N34-Th33 & 123.726 & Th33-O37-C14-C11 & -10.177 \\
\hline Th33-N37 & 2.272 & C14-C37-Th33 & 113.215 & Th33-N34-C27-C20 & 171.685 \\
\hline H32-C31 & 1.07 & H32-C31-C26 & 120.008 & H32-C31-C26-C19 & -179.974 \\
\hline C31-C26 & 1.359 & C31-C26-C19 & 120.926 & C31-C26-C19-C18 & 179.725 \\
\hline C30-C27 & 1.436 & C30-C27-C20 & 119.602 & C30-C27-C20-C19 & 0.623 \\
\hline H29-C22 & 1.70 & H29-C22-C21 & 120.006 & H29-C22-C21-C20 & -179.966 \\
\hline H28-C21 & 1.07 & H28-C21-C20 & 120.007 & H28-C21-C20-C19 & -179.957 \\
\hline C27-C20 & 1.397 & C27-C20-C19 & 119.776 & C27-C20-C19-C18 & 179.870 \\
\hline C26-C19 & 1.408 & C26-C19-C18 & 119.552 & C26-C19-C18-C17 & -179.94 \\
\hline H25-C18 & 1.07 & H25-C18-C17 & 119.94 & H25-C18-C17-C22 & -179.998 \\
\hline H24-C17 & 1.07 & H24-C17-C18 & 119.972 & H24-C17-C22-C21 & 179.972 \\
\hline C2-C1 & 1.355 & C1-C2-C3 & 120.120 & C4-C3-C2-C1 & -0.0613 \\
\hline C3-C2 & 1.401 & C2-C3-C4 & 119.700 & C5-C4-C3-C2 & 0.0834 \\
\hline C4-C3 & 1.358 & C5-C4-C3 & 120.151 & C6-C5-C4-C3 & -0.0493 \\
\hline C5-C4 & 1.401 & 6C-C5-C4 & 119.985 & H8-C3-C2-C1 & -179.998 \\
\hline C6-C5 & 1.354 & C10-C3-C2 & 119.522 & C10-C3-C2-C1 & 179.988 \\
\hline H7-C10 & 1.070 & H8-C1-C2 & 119.972 & C11-C4-C3-C2 & -179.871 \\
\hline H8-C1 & 1.07 & C11-C4-C3 & 119.776 & H12-C5-C4-C3 & 179.995 \\
\hline & & & & & \\
\hline
\end{tabular}

The CNO angle in typical oximes is relatively constant around $112-113^{\circ}(14,15)$. In the present chelate the C27$\mathrm{N} 34-\mathrm{O} 39$ angle is opened up by about $10^{\circ}$ from the expected value and found constant for all four angles. The naphthalene carbon ring is relatively planar, the largest deviation from the mean plane being $0.023 \mathrm{~A}^{\circ}$ for the 
$\mathrm{C} 1$ carbon atom. The $\mathrm{N}$ and $\mathrm{O}$ atoms lie approximately in the naphthalene mean plane. A further interesting finding is that the outside angle C4-C11-N25 $\left[121.392^{\circ}\right]$ is significantly larger than the inside angle C14-C11N35 [ $\left.119.001^{\circ}\right]$. It may be noted that almost the same differences are predicted. It is obvious that the only marked distortions of the geometry and orientation of the present 1,2-oxime groups are associated with the oxime groups on the carbon atom.Fig.2 shows atomic charges of atoms.

\section{Mulliken Atomic Charges}

Mulliken charges arise from the Mulliken population analysis $(16,17)$ and provide a means of estimating partial atomic charges from calculations carried out by the methods of computational chemistry, particularly those based on the linear combination of atomic orbitals molecular orbital method, and are routinely used as variables in linear regression QSAR procedures(18).

In the application of quantum mechanical calculation to molecular system, the calculation of effective atomic charges plays an important role. The electron distribution of $\mathrm{Th}(\mathrm{NQO})_{2}$ is compared in the two different mechanical methods and the sensitivity of the calculated charges to charge in choice of methods is studied. By determining electron population of each atom in the defined basis function, the Mulliken charges are calculated by HF/SDD. The results are presented in Table-3 which the values of atomic charges of each atom of the concerned molecule. Fig. 2 shows Atomic charge against atoms of the said molecule.

Table-3:- Mulliken Atomic Charges of Th (NQO) 2

\begin{tabular}{|c|c|c|c|c|c|}
\hline $\begin{array}{l}\text { Sr. } \\
\text { No. }\end{array}$ & Atom & Atomic charge & Sr. No. & Atom & $\begin{array}{l}\text { Atomic } \\
\text { charge }\end{array}$ \\
\hline 1 & $1 \mathrm{C}$ & -0.251275 & 22 & $22 \mathrm{C}$ & -0.326573 \\
\hline 2 & $2 \mathrm{C}$ & -0.410219 & 23 & $23 \mathrm{H}$ & 0.216324 \\
\hline 3 & $3 \mathrm{C}$ & 0.413605 & 24 & $24 \mathrm{H}$ & 0.213478 \\
\hline 4 & $4 \mathrm{C}$ & 0.144949 & 25 & $25 \mathrm{H}$ & 0.218348 \\
\hline 5 & $5 \mathrm{C}$ & -0.279177 & 26 & $26 \mathrm{C}$ & -0.449054 \\
\hline 6 & $6 \mathrm{C}$ & -0.332238 & 27 & $27 \mathrm{C}$ & 0.229270 \\
\hline 7 & $7 \mathrm{H}$ & 0.213163 & 28 & $28 \mathrm{H}$ & 0.201822 \\
\hline 8 & $8 \mathrm{H}$ & 0.207409 & 29 & $29 \mathrm{H}$ & 0.208906 \\
\hline 9 & $9 \mathrm{H}$ & 0.213888 & 30 & $30 \mathrm{C}$ & 0.364040 \\
\hline 10 & $10 \mathrm{C}$ & -0.455942 & 31 & $31 \mathrm{C}$ & -0.402844 \\
\hline 11 & $11 \mathrm{C}$ & 0.233087 & 32 & $32 \mathrm{H}$ & 0.235988 \\
\hline 12 & $12 \mathrm{H}$ & 0.312284 & 33 & $33 \mathrm{Th}$ & 2.210392 \\
\hline 13 & $13 \mathrm{H}$ & 0.206175 & 34 & $34 \mathrm{~N}$ & -0.651137 \\
\hline 14 & $14 \mathrm{C}$ & 0.357746 & 35 & $35 \mathrm{~N}$ & -0.608482 \\
\hline 15 & $15 \mathrm{C}$ & -0.401937 & 36 & $36 \mathrm{O}$ & -0.731165 \\
\hline 16 & $16 \mathrm{H}$ & 0.230802 & 37 & $37 \mathrm{O}$ & -0.730705 \\
\hline 17 & $17 \mathrm{C}$ & -0.260260 & 38 & $38 \mathrm{O}$ & -0.614829 \\
\hline 18 & $18 \mathrm{C}$ & -0.399351 & 39 & $39 \mathrm{O}$ & -0.578630 \\
\hline 19 & $19 \mathrm{C}$ & 0.404330 & 40 & $40 \mathrm{H}$ & 0.490436 \\
\hline 20 & $20 \mathrm{C}$ & 0.195699 & 41 & $41 \mathrm{H}$ & 0.429844 \\
\hline 21 & $21 \mathrm{C}$ & -0.268169 & & & \\
\hline & & & & & \\
\hline
\end{tabular}

Fig.2 Atomic charge on each atom

HOMO-LUMO energy gap and related molecular properties.

The HOMO-LUMO energy gap of the molecule Th(NQO $)_{2}$ in the HF and SDD basis set has been calculated. The HOMO-LUMO energy gap is constant in both methods. It is known that the value of EHOMO is often associated with the electron donating ability of inhibitor molecule, higher values of $E H O M O$ is an indication of the greater ease of donating electrons to the unoccupied d orbital of the receptor. The value of $E$ LUMO is related to the ability of the molecule to accept electrons, lower values of ELUMO shows the receptor would accept electrons. Consequently, the value of Egap provides a measure for the stability of the formed complex on the metal surface. The frame work of SCF MO theory, the ionization energy and electron affinity can be expressed through HOMO and LUMO energies AS I= - $\mathrm{E}_{\text {номо, }} \mathrm{A}=-\mathrm{E}_{\mathrm{LUmo}}$. The hardness compounds to the gap between the HOMO and LUMO orbital energies. If the gap energy is higher than the Hardness is also larger. The global hardness $\eta=1 / 2\left(\mathrm{E}_{\text {номо- }} \mathrm{E}_{\text {LUмо }}\right)$. The hardness is associated with the stability of chemical potential $(\mu)$ can be expressed in combination of electron affinity and ionization potential. The global electrophilicity index $\left(_{\omega}\right)$ is also calculated and listed in table- 4 . 
The chelate formation of thorium with 1, 2-naphthoquinone, 1-oxime

Table No: - 4 Comparison of HOMO-LUMO, Energy gap and related Molecular Properties of Th(NQO) 2

\begin{tabular}{|c|c|}
\hline Molecular Properties & HF/SDD \\
\hline HOMO eV & -0.22404 \\
\hline LUMO eV & -0.03485 \\
\hline Energy gap & 0.18559 \\
\hline Ionisation Potential $(\mathrm{I})$ & 0.22404 \\
\hline Electron Affinity(A) & 0.03485 \\
\hline Global Hardness $(\eta)$ & 0.09279 \\
\hline Chemical Potential $(\mu)$ & 0.09279 \\
\hline Global Electrophilicity $(\omega)$ & 0.04639 \\
\hline
\end{tabular}

Thermodynamic properties

On the basis of vibrational analysis at B3LYP / SDD and HF / SDD level, several thermodynamic parameters are calculated and are presented in Tabl-5. The zero point vibration energy (ZPVE) and the entropy, Svib.(T) are calculated to the extent of accuracy and the variations in ZPVE seem to be insignificant. The total energy and the change in total entropy of $\mathrm{Th}(\mathrm{NQO})_{2}$ at room temperature at different methods is only marginal.

Table 5 Theoretically computed Energies (a.u.), Zero point Energy ( Kcal / mol) Rotational Constants $(\mathrm{GHz})$,Entropy $\left(\mathrm{cal} \mathrm{mlo}^{-1} \mathrm{~K}^{-1}\right.$ ) and Dipole moment D ( Kcal. $\mathrm{mlo}^{-1} \mathrm{~K}^{-1}$ )

\begin{tabular}{|c|c|}
\hline Parameter & DFT/B3LYP/SDD \\
\hline Total Energy e.u. & -1579.406 \\
\hline Zero Point Energy & 206.305 \\
\hline Rotational constants & 0.34303 \\
\hline & 0.04830 \\
\hline & 0.07317 \\
\hline Entropy Total & 125.549 \\
\hline Translational & 44.948 \\
\hline Rotational & 36.272 \\
\hline vibrational & 36.373 \\
\hline Dipole movement (D) & 9.2314 \\
\hline
\end{tabular}

\section{Conclusions}

The calculated vibration frequencies are compared with experimental data and found most of them are in good aggriment. The assignments were confirmed with the help of animation process which is available in Gaussian 09 computer code. The results suggest that it shows the formation of chelates. The molecular geometry of Th (NQO) $)_{2}$ is best at the HF/ SDD level. The HOMO- LUMO energy was calculated and other related molecular properties were also discussed. The Mullikan atomic charges were calculated and the results were discussed. Thermodynamic parameters were calculated.

\section{Acknowledgement}

We thank Prin. K.D. Jadhav, Principal, Bharati Vidyapeeth Deemed University, Yashwantrao Mohite College, Pune for permission to Publish this work.RGS and GSJ are grateful to U.G.C. for providing financial assistance by Major Research Project [F. No. 40-84/2011(SR)].

\section{References}

[1]. Dyrssen, D. and Johansson, E. Acta. Chem. Scand., 9, 763 (1955).

[2]. B.G. Brown, Prog. Inorg. Chem., 18, 17 (1873).

[3]. E. Wong, and C.M. Giandomenico, Chem. Rev., 99(9): 2451-2466(1999).

[4]. V. B. Jadhav, N.R. Gonewar, K.D. Jadhav and R.G. Sarawadekar, Investigation on theoretical calculations of mid-far infrared, NMR and electronic spectra of 1-nitroso-2, naphthol or 1-2 naphthoquinine-1, oxime and comparison with experimental data, J. Pharmacy Research, 4(12) 4553-4555.

[5]. R. M. Elofson and J. G. Atkinson, The polarography of the monoximes and dioximes of benzoquinone, naphthoquinone, and anthraquinone, Canadian Journal of Chemistry, 34(1): 4-13, 10.1139/v56-002 (1956),

[6]. G. S. Jagtap, N. S. Suryawanshi, K. D. Jadhav, R. G. Sarawadekar, Ab initio, Hartree- Fock and Density Functional Theoretical study of vibrational spectra of zirconium chelate of 1,2-naphthoquinone -2, oxime, IOSR Journal of Applied Chemistry (IOSRJAC) Volume 2, Issue 5, pp 52-60 (Nov. - Dec. 2012),

[7]. H. B. Schleqel, J. Comput. Chem. 3,124 (1982).

[8]. P. Hohenberg and W. Kohn, Phy. Rev. 136, B 864 (1964).

[9]. D. Beeke, J.Chem. Phys, 98, 5648 (1993).

[10]. C.Lee, W.Yang and R.G. Parr, Phy. Rev., B37, 785(1998).

[11]. G.Varsayani, Assignment for Vibration Spectra of Seven hundred number Benzene derivatives Vol. 1 \& 2 Academic Kiqclo Budapest, (1973).

[12]. N.P.G. Roeges, A guide to the complete interpretation of Intrared spectra of organic compounds, Wiley, New York (1994). 
[13]. G. Varsanyi and P. Sohar, Acta. Chim. Acad. Sci. Hung., 74, 315 (1972).

[14]. V. R. Constantino, H.E.Toma, L.F.C.Oli venia and P. S. Santos, Raman Spectroscopy, 23,629(1992).

[15]. C. Natrajan and A. Nazeer Hussain, Indian J. Chem. 22A,527 (1983).

[16]. R. S. Mulliken, "Electronic Population Analysis on LCAO-MO Molecular Wave Functions. I". The Journal of Chemical Physics 23 (10): 1833-1831(1955).

[17]. H. Saarinen, J. Korvenranta and E. Nasakkala, Acta. Chem. Scand., A 31, 213 (1977).

[18]. A. Chakravorty, Coord. Chem. Rev., 13, 1 (1974). 